\title{
EXPRESSÕES EMOCIONAIS ENTRE BEBÊS NA CRECHE: REVISÂO SISTEMÁTICA DA LITERATURA
}

EMOTIONAL EXPRESSION AMONG INFANTS IN A NURSERY CARE INSTITUTION: SYSTEMATIC LITERATURE REVIEW

\section{EXPRESIONES EMOCIONALES ENTRE BEBÉS EN LA GUARDERÍA DE NIÑOS: REVISIÓN SISTEMÁTICA DE LA LITERATURA}

Marisa von Dentz*

Katia de Souza Amorim **

\begin{abstract}
RESUMO
$\mathrm{O}$ artigo apresenta uma revisão sistemática sobre a expressividade emocional entre pares de bebês de creche. Aquela foi conduzida por meio de diversas bases de dados (Scielo, Pepsic, Lilacs, Psycinfo e Eric), pelo cruzamento das palavras-chave "bebê(\$)", "baby", "infant development", "interação", "social interaction", "emoção", "facial expression", "emotion", "creche", "day care" e "nursery", sendo resgatados 24 artigos indexados. A maioria dos trabalhos são empíricos, de perspectiva qualitativa, reconhecendo as expressividades emocionais dos bebês exclusivamente na face e em sua relação com adultos. Dentre as conclusões, destaca-se a importância de trabalhos que acompanhem longitudinalmente as interações de pares de bebês, considerando toda a corporeidade da criança, não apenas a face. Sob a hipótese de que há uma riqueza de expressividades emocionais nas interações de bebês em creche, já no primeiro ano de vida, aponta-se para a relevância de estudos futuros sobre esta temática investigativa.
\end{abstract}

Palavras-chave: Bebês. Expressividade emocional. Creche. Revisão.

\begin{abstract}
This paper presents a systematic literature review on emotional expression among pairs of infants interacting in a day care institution. The following databases were applied: Scielo, Pepsic, Lilacs, Psycinfo, and Eric, by matching the keywords "bebê(\$)", "baby", "infant development", "interação", "social interaction", "emoção", "facial expression", "emotion”, "creche”, "day care" and "nursery". A total of 24 studies were analyzed. Most studies are empirical, with qualitative perspective recognizing the babies' emotional
\end{abstract}

\footnotetext{
Texto recebido em 6 de março de 2016 e aprovado para publicação em 21 de outubro de 2016.

*Doutoranda no Departamento de Psicologia da Faculdade de Filosofia, Ciências e Letras de Ribeirão Preto, da Universidade de São Paulo (USP), mestra em Psicologia pela mesma instituição, graduada em Psicologia pela Universidade de Franca (Unifran). E-mail:marisadentz@gmail.com.

"Professora doutora no Departamento de Psicologia da Faculdade de Filosofia, Ciências e Letras de Ribeirão Preto - Universidade de São Paulo. E-mail: katiamorim@ffclrp.usp.br.
} 
expressivity exclusively on the face and in their relationship with adults. The conclusion highlights the importance of works that follow longitudinally interaction of pairs of infants, considering not only the face but all the child's corporeality. Having in mind the assumption that there is a variety of emotional expressivity in babies' interaction at a day care nursery institution, in the first year of life, future studies approaching the subject are yet required.

Keywords: Babies. Emotional expression. Day care nursery institution. Review.

\section{RESUMEN}

El artículo presenta revisión sistemática sobre la expresividad emocional entre pares de niños de guardería. La revisión fue conducida por las bases de datos Scielo, Pepsic, Lilacs, Psycinfo y Eric, por la mescla de las palabras clave "bebêe(\$)", "baby", "infant development", "interação", "social interaction", "emoção", "facial expression", "emotion", "creche", "day care" e "nursery", siendo rescatados 24 artículos. La mayoría de los trabajos son empíricos, de perspectiva cualitativa y reconocen la expresividad emocional de los bebés exclusivamente en la cara y en su relación con los adultos. La conclusión pone de relieve la importancia de pesquisas que acompañen longitudinalmente a los bebés en interacción, teniendo en cuenta toda la corporeidad del niño, no solo la cara. Bajo el supuesto de que existe una gran cantidad de expresividad emocional en la interacción infantil en la guardería, en el primer año de vida, se apunta a la importancia de estudios futuros sobre este tema de investigación.

Palabras clave: Bebés. Expresividad emocional. Guardería. Revisión.

\section{INTRODUÇÃO}

$\mathrm{N}$

ovas configuraçóes socioeconômicas e culturais têm levado, de forma crescente, a que a mulher/mãe passe a trabalhar fora de casa, buscando soluções alternativas e complementares ao cuidado e à educação dos filhos, inclusive de bebês. Uma das alternativas de compartilhamento tem sido com instituições do tipo creche (Amorim \& Rossetti-Ferreira, 1999b; Amorim, Vitória \& Rosetti-Ferreira, 2000). Dessa realidade social, passou-se a constituir novas relações para o bebê, exigindo nacional e internacionalmente a busca por compreender como se dão as relações nos espaços de educação infantil coletiva.

Essa busca se deu, pois a participação do bebê na creche, particularmente em longas jornadas, tem sido vista por muitos psicólogos como não favorável ao desenvolvimento afetivo e social do bebê (Belsky, 2009; Bowlby, 1969), já 
que, historicamente, o contexto de desenvolvimento considerado ideal à criança pequena é a casa, com a mãe. Nas instituições coletivas, porém, a relação adultocriança é mais baixa, o par de idade sendo o parceiro mais frequente da criança. Com isso as interações de pares de bebês têm ganhado crescente foco e interesse (Rossetti-Ferreira, Oliveira, Campos-de-Carvalho, \& Amorim, 2010).

As interaçôes de crianças nos dois primeiros anos de vida com seus coetâneos, no entanto, não só têm sido pouco investigadas como a ocorrência da interação de pares de bebês não é usualmente reconhecida. Como afirmam Brownell, Ramani e Zerwas (2006), a cooperação entre crianças de 1 ano de idade parece ser mais coincidência, enquanto que crianças mais velhas parecem mais ativamente cooperar em direção a uma meta. Os autores concluem, assim, que a habilidade de cooperar com seus pares, tornando-se verdadeiro parceiro social, desenvolvese depois do segundo e terceiro ano de vida.

Porém, por meio de diferentes referenciais e metodologias, outros estudos vêm apontando a ocorrência de interações entre pares de idade, ocorrendo, inclusive, de maneira bastante precoce (Amorim, Anjos \& Rossetti-Ferreira, 2012; Anjos, Amorim, Vasconcelos, \& Rossetti-Ferreira, 2004; Costa \& Amorim, 2015). Nessas propostas, essas interações têm sido analisadas considerando a corporeidade do bebê (Amorim \& Rossetti-Ferreira, 2008), em que se destacam as diversas manifestações deste, particularmente as emocionais.

O tema das emoções em bebês vem sendo discutido desde longa data (Darwin, 2000), particularmente na Psicologia do Desenvolvimento (Bergamasco, 1997; Brannigan \& Humphries, 1981; Galvão, 2003; Garvey \& Silva, 2010; Mendes \& Moura, 2009; Mendes \& Seidl-de-Moura, 2009; Wallon, 1999, entre outros).

$\mathrm{O}$ interesse pelo estudo das emoções, principalmente na criança pequena, tem sido feito também com foco científico nos processos cognitivos, inclusive no campo das neurociências (Esperidião-Antonio et al., 2008). Também é destaque na área médica pela necessidade do diagnóstico de dor em recém-nascidos, como na Unidade de Terapia Intensiva (UTI) neonatal (Balda, Almeida, Peres, \& Guinsburg, 2009).

Partindo da Psicologia do Desenvolvimento, Mendes e Moura (2009) afirmam que o desafio contemporâneo da área é considerar o sistema de emoções nas interaçốes afetivas, como contexto privilegiado de desenvolvimento. Mendes e Seidl-de-Moura (2009) discutem, nesse sentido, a ontogênese das expressões emocionais e seus mecanismos de produção, regulação e percepção pelo bebê de expressões faciais de emoção importantes para o desenvolvimento da própria emoção e da constituição da intersubjetividade. Segundo elas, desde o nascimento, o papel das interações envolvendo expressões faciais de emoção é 
considerado como decisivo para o processo de desenvolvimento da referência social.

Autor considerado central no campo é Wallon (1979; 1999). Partindo de uma abordagem materialista dialética e orientado por uma visão integrada do desenvolvimento humano, Wallon afirma que as emoçôes têm um lugar central na psicogenética (Galvão, 2003). Tal importância se deve, segundo Wallon (1979), pelo fato de que, no ser humano, existe um período de imperícia prolongada na infância, em que o outro é condição fundamental da sobrevivência da criança humana (Wallon, 1999).

De acordo com Galvão (2003), mesmo mediante expressões emocionais bem primitivas, como o sorriso e o choro, o bebê humano mobiliza as pessoas de seu entorno numa espécie de contágio afetivo, levando o adulto a atribuir significados a tais expressões, o que resulta em ações junto ao bebê. Galvão volta, assim, sua atenção para os efeitos da expressividade sobre o corpo como um todo. Nesse sentido, destaca que o gesto, estabilizado em postura, em atitude corporal, exprime as disposiçôes afetivas. Assim, já os primeiros movimentos do recémnascido (impulsos, espasmos, reflexos) são expressivos, pela coloração afetiva que carregam ao sinalizar disposições individuais. Essas manifestações tendem a causar impacto no meio humano, que interpreta as expressôes e reage de acordo com a interpretação. Desse jogo entre indivíduo e meio, vão se constituindo significados para as expressões, que vão passando a constituir emoções mais definidas e diferenciadas.

Considerando o processo dialógico relacional na base da emoção, autores como Garvey e Silva (2010) discutem que as emoções ajudam a pontuar a posição da pessoa no dinâmico fluxo de comunicação, levando à abertura ou ao fechamento em relação aos outros, conectando-se ou se desconectando dos outros. Dessa maneira, a emoção aparece em um campo que não olha somente o bebê, mas apreende as emoções deste pelas relações que estabelece, mostrando-se social, cultural.

Porém, de modo geral, as emoções dos bebês têm sido estudadas centralmente nas relações com os adultos, mais particularmente a mãe. Esse foco se deve ao lugar considerado central da mãe, à relação, ao cuidado e ao papel no desenvolvimento da criança (Bowlby, 1969; 1989; Freud, 1969; Winnicott, 1987, entre outros). De forma dominante, pontua-se que a mãe ocupa papel fundamental no desenvolvimento do bebê, sendo ela quem deva proporcionar oportunidades para descobertas e favorecer explorações do bebê (Beebe, 1982; Mendes \& Moura, 2009; Moura \& Ribas, 2000).

Carvalho (2005) e Lewis (2005), porém, afirmam que as crianças parceiras 
de idade têm funções complementares as dos adultos, sendo que, em certos aspectos, são mais eficazes na construção de conhecimentos compartilhados, na participação da dinâmica do relacionamento e desenvolvimento de habilidades sociais. Para isso, os autores destacam as emoçôes e a afetividade nos processos e na relação entre as crianças.

Dessa maneira, frente a realidade social que tem impulsionado bebês a uma participação bastante precoce em instituições coletivas de educação; e, diante de posições contraditórias à participação do bebê na creche, associado ao pouco conhecimento das possibilidades interativas dos bebês com os pares, buscou-se compreender como as expressividades emocionais entre bebês em creche têm sido investigadas e definidas na literatura. Para isso, conduziu-se revisão bibliográfica sobre $o$ assunto, sendo aqui apresentada.

\section{MÉTODO}

A revisão bibliográfica foi realizada entre agosto e novembro de 2015. A pergunta problema incialmente posta na revisão foi: como a literatura vem investigando e analisando processos de manifestações emocionais entre pares de bebês em creche? Porém, após série ampla de buscas, sem obter material, modificou-se a pergunta-base, dando-lhe certa ampliação, de modo a posteriormente derivar o tema central. Assim, passou a ser: como a literatura vem investigando e analisando os processos e manifestações emocionais de bebês?

Para as buscas, utilizou-se do portal Biblioteca Virtual em Saúde (BVS) Psicologia Brasil, as bases Scientific Eletronic Library Online (Scielo) e Periódicos Eletrônicos de Psicologia (Pepsic); e, em sua própria fonte, a base de dados Lilacs. Com o intuito de verificar a literatura internacional, utilizou-se a base de dados a Associação Americana de Psicologia (Psycinfo). Ainda, por se tratar de questão relacionada à educação infantil, recorreu-se à base Education Resources Information Center (ERIC). As palavras selecionadas e cruzadas para as buscas foram: bebê(\$), baby, infant development, interação, social interaction, emoção, facial expression, emotion, creche, daycare e nursery.

Para estabelecer critérios e filtros de seleção dos trabalhos que se aproximassem da discussão das expressões emocionais de bebês (preferencialmente em creche), elencamos os seguintes critérios de inclusão dos estudos:

a) artigos que estudam bebês humanos: foco nos primeiros anos de vida e sem limitação de data de publicação;

b) artigos em que o bebê aparece como agente da emoção, aquele que expressa a emoção, preferencialmente em creche e com o par. Incluíram-se, 
assim, artigos relacionados à expressividade emocional em bebês em outras relações e, ou, contextos;

c) artigos que discutam as expressões emocionais em bebês de forma geral ou alguma expressão específica na primeira infância, com foco no primeiro ano de vida; e

d) artigos publicados em português, inglês, espanhol e francês.

Como critérios de exclusão, foram definidos trabalhos publicados em idiomas que não o português, inglês, francês e espanhol; artigos que abordavam processos emocionais envolvendo crianças mais velhas; e, ainda, trabalhos em formato de teses/livros.

Após a leitura integral dos textos selecionados, seus dados foram organizados em planilha do Excel, destacando-se aspectos cujos resultados são aqui apresentados e discutidos na sequência.

\section{RESULTADOS E DISCUSSÃO}

Os artigos selecionados a partir dos critérios de inclusão e exclusão foram 24. Na sequência, apresentam-se e discutem-se questôes analisadas relativas aos locais e ao fluxo das publicaçôes, metodologias envolvidas, formas de abordar as emoções nos bebês e as contribuições/limites da literatura e desta revisão para essa temática.

\subsection{Dos países onde foram publicados os estudos}

Entre os trabalhos, observou-se que a maior parte dos estudos encontrados foram produzidos no Brasil (17) e na França (2). Demais países, como Holanda, Estados Unidos, Espanha, Dinamarca e Austrália, apresentaram apenas um artigo publicado.

Vale considerar que o alto número de artigos publicados no Brasil não significa que o País seja pioneiro no estudo da emoção entre pares de bebês de creche, mesmo porque, também no Brasil, não foram encontrados trabalhos que especificamente tratassem dessa temática. Mas, segundo os textos encontrados, o Brasil é o país que apresenta maior quantidade de trabalhos que se aproximam da temática e que, implicitamente, citam ocorrências de expressividades emocionais entre pares de bebês de creche. Tais estudos serão mais bem detalhados adiante.

Quanto à escassez de trabalhos no exterior, a hipótese é de que os resultados se relacionam a questôes políticas, organização social e concepçôes sobre ambientes adequados para crianças pequenas em outros países. Como discutido por 
Amorim e Rossetti-Ferreira (1999a), pesquisadores/políticos, particularmente norte-americanos e ligados a alguns países europeus (como Inglaterra), culturalmente valorizam o cuidado da criança pequena pela mãe e em domicílio, em detrimento de ambientes coletivos, questionando a creche como lugar adequado para o cuidado das crianças pequenas (Belsky, 2009; Early Child Care Research Network, 2007).

Essas perspectivas sobre cuidado ideal da criança pequena (que se materializam inclusive em termos de políticas públicas) são claramente verificadas no estudo de Rutanen, Amorim, Colus e Piattoeva (2014). As autoras analisaram políticas do Brasil e da Finlândia relacionadas aos cuidados e à educação para crianças de 0 a 3 anos de idade. $\mathrm{O}$ trabalho discute que, no Brasil, as preocupações estão relacionadas ao aumento da assistência e do cuidado da criança pequena por meio de instituições de educação infantil. Já na Finlândia, a discussão é como melhor desenvolver a atenção domiciliar com apoio financeiro do Estado, já que, ali, o cuidado domiciliar é visto como o mais adequado para a criança de 0 a 3 anos de idade.

Já em países como França e Israel, a instituição creche se encontra mais enraizada (Amorim \& Rossetti-Ferreira, 1999a). Pelos resultados desta revisão bibliográfica, na ordem de maior número de trabalhos encontrados, após o Brasil, temos a França. Já de Israel não nos foi possível acessar estudos, esse fato podendo estar relacionado às bases de dados investigadas.

Os trabalhos franceses encontrados, porém, foram desenvolvidos três a quatro décadas atrás (1978 e 1983) e precedem o fluxo de publicações sobre interação entre pares de bebês no Brasil (1990 a 2014). Isso leva a supor que devam existir outras investigações na França sobre expressividades entre bebês em creche. No entanto não foi possível ter acesso, pelo limite dado em uma revisão, em função da (im)possibilidade de acesso a bancos de dados mais ligados àquele país. Tal inquietação aponta para a necessidade de novas buscas.

Além dos trabalhos franceses, os outros desenvolvidos e publicados em países estrangeiros mencionam questóes relacionadas à sociabilidade entre bebês. Entretanto somente alguns dos trabalhos, discutidos mais adiante, discorrem sobre expressões emocionais entre pares.

Dando sequência, discute-se o fluxo de publicaçôes ligadas a essa temática, nas últimas décadas.

\subsection{Fluxo de publicações}

Dos trabalhos analisados, verificaram-se algumas décadas em que ocorreu um 
fluxo maior de publicações em detrimentos de outras. Na década de 1970, houve duas publicaçôes; na década de 1980, houve apenas um trabalho localizado; e, na década de 1990, três trabalhos. Já a partir de 2000, encontrou-se um fluxo maior de publicações (12 artigos), e esse número se mantém crescente, com seis trabalhos publicados entre 2010 e 2015.

Mendes e Moura (2009) afirmam que, na Psicologia, o estudo das emoçóes e da afetividade passou por ocasiōes de aproximações e distanciamentos, tendo contado, inclusive, com momentos de quase completo abandono do assunto. Entretanto, segundo as autoras, nas últimas décadas, tem ocorrido crescente retomada do tema como objeto de formulação teórica. O interesse crescente pelas expressões emocionais de bebês parece ser reflexo daquelas novas perspectivas de estudos, que contam inclusive com o uso de novas tecnologias de investigação (Carvalho et al., 1996), que têm permitido verificar novas evidências de competências do bebê (Ribeiro, Bussab, \& Otta, 2004).

Dos artigos recuperados expõe-se alguns de seus aspectos.

\subsection{Tipos de trabalhos encontrados e questões metodológicas}

Dos 24 artigos analisados, 18 (75\%) deles baseiam-se em dados empíricos; 5 (21\%) discutem teorias relacionadas a aspectos do desenvolvimento na primeira infância; e 1 trabalho se refere a uma revisão bibliográfica sistemática da literatura.

O trabalho de revisão bibliográfica (Mendes \& Moura, 2009) constituiu-se um apoio para a discussão das expressões emocionais em bebês. A revisão resgata a literatura precedente, em que as emoções são reconhecidas predominantemente na face das crianças. Apesar das contribuições, os trabalhos analisados não avançam em relação a algumas das compreensões mais atuais, referentes ao reconhecimento das emoçôes para além da face e perpassando por toda a corporeidade da criança (Ferreira, 2013). Tampouco é tratada a expressividade emocional entre pares de bebês em ambientes de educação coletiva.

Já os artigos teóricos tratam de uma variedade de assuntos: vida social rica entre bebês, sem a intervenção necessária do adulto (Lima, 2012); reduções teóricas como empecilho para compreensão global da criança (Reis, 1991); e separação precoce e consequências ao desenvolvimento (Rapoport \& Piccinini, 2001). Um artigo (Mendes \& Seidl-de-Moura, 2009) discute especificamente as origens da expressão do sorriso em bebês, apontando para evidências de que este contém tanto aspectos inatos como adquiridos pela cultura. No entanto não trata o sorriso dos bebês em ambiente coletivo.

Os artigos teóricos mencionados trazem implicitamente expressões emocionais 
do bebê, tais como sorriso, choro, afeto positivo e negativo, irritação, entre outros. Mas as discussōes envolvem questôes práticas e de desenvolvimento, em diferentes ambientes (incluindo creche), sem foco nas emoções entre os pares de bebês.

Os estudos empíricos compreendem 18 (75\%) dos 24 trabalhos analisados. Um dos aspectos de sua análise buscou verificar a abordagem metodológica usada na realização das pesquisas: quantitativa, qualitativa ou quantitativa/qualitativa.

Encontrou-se tendência predominante de estudos com base em abordagens qualitativas (Amorim, 2012; Amorim, Anjos, \& Rossetti-Ferreira, 2012; Amorim, Costa, Rodrigues, Moura, \& Ferreira, 2012; Anjos et al. 2004; Melchiori \& Alves, 2004; Nyland, 1999; Pantoja \& Nelson-Goens, 2000; Rouchouse, 1978, Saullo, Rossetti-Ferreira, \& Amorim, 2013; Vasconcelos, Amorim, Anjos, \& Ferreira, 2003;

Weltzer, 1985; Zanella \& Andrada, 2002) em detrimento das qualitativas/ quantitativas (Finkelstein, Dent, Gallacher, \& Ramey, 1978; Melchiori \& Alves, 2000; Melchiori \& Biasoli-Alves, 2002) e quantitativas (Chóliz, FernándezAbascal, \& Martínez-Sánchez, 2012; Deynoot-Schaub \& Riksen-Walraven, 2006; Bergamasco, 1997).

Entre esses 18 trabalhos empíricos, 14 deles articulam videogravação com outros métodos de registro. Assim, cinco deles também fazem uso de entrevistas (Saullo et al., 2013; Amorim, 2012; Amorim, Anjos \& Rossetti-Ferreira, 2012; Amorim, Costa et al., 2012; Melchiori \& Alves, 2000). Além desses, encontrouse um que se utiliza apenas de entrevistas (Melchiori \& Alves, 2004) e outro que combina entrevistas e observação/diário de campo (Melchiori \& Biasoli-Alves, 2002). Têm-se ainda dois trabalhos (Deynoot-Schaub \& Riksen-Walraven, 2006; Finkelstein et al., 1978) que se utilizam de testes padronizados, um deles combinado com a videogravação (Deynoot-Schaub \& Riksen-Walraven, 2006).

A análise revelou, portanto, que a videogravação foi a técnica de coleta de dados mais utilizada, independentemente de terem estudado por abordagem quanti ou qualitativa. Isso levanta questôes quanto à pertinência de videogravaçôes para o estudo das expressividades emocionais em bebês e crianças pequenas. Essa técnica tem sido considerada como uma ferramenta importante para avanços na área, já que o recurso garante a preservação do fenômeno (Carvalho et al., 1996). Como discute Beebe (1982), os eventos comunicativos do bebê ocorrem muito rapidamente, o vídeo e sua microanálise permitindo capturá-los e discernir pela sua significância comunicativa.

Ouso das videogravações, porém, mostrou-sebastantevariável, particularmente 
em termos de tempo de registro, esse aspecto estando estreitamente ligado ao referencial e ao tipo de pergunta que se propunha a responder. Assim, há trabalhos que coletaram dados uma única vez e, ou, por um curto período, como no estudo de Finkelstein et al. (1978) que realizou oito minutos de gravação diária, por cinco dias consecutivos, para investigar a mudanças de comportamento social em razão da idade; ou videogravação dos dez primeiros segundos do choro de bebês (uma única vez), para descrever diferentes choros diante do medo, enfado e dor, considerando a precisão das reações dos adultos (Chóliz, FernándezAbascal, \& Martínez-Sánchez, 2012); ou ainda, videogravaçôes de dez minutos, para verificar comportamentos diante da separação dos pais na frequência à creche (Melchiori \& Alves, 2000).

Outros trabalhos se utilizaram de período mais prolongado de registro. Alguns estudos analisaram videogravações do projeto Processos de adaptação de bebês a creche (Rossetti-Ferreira, Amorim, \& Vitória, 1994). Neste, 21 bebês de uma creche foram filmados diariamente por três meses, com três horas de gravaçôes diárias, contando com 72 horas de gravação (Vasconcelos et al., 2003; Anjos et al., 2004; Amorim, Anjos et al., 2012; Amorim, Costa et al., 2012). Por um acompanhamento longitudinal, os trabalhos discutem processos de transformação e desenvolvimento, os quais envolvem interações de bebês, significação, relações afetivas e mediação. Acrescenta-se, ainda, a pesquisa de Pantoja e Nelson-Goens (2000), em que mãe e bebê foram filmados em laboratório três vezes por semana, por três meses, para investigar mudanças da vida emocional nas interações da díade.

Já o estudo transversal de Deynoot-Schaub e Riksen-Walraven (2006) descreve videogravações de bebês de creche por 90 minutos, aos 15 meses e aos 24 meses, também empregando instrumentos de avaliação para medir a ocorrência de estabilidade emocional entre os pares de bebês e a qualidade dos cuidados.

Entretanto, em se tratando de pesquisas relacionadas a aspectos do desenvolvimento de bebês, as quais buscam investigar processos que se transformam ao longo do tempo, as pesquisas longitudinais colocaram-se como centrais. De acordo com Mota (2010), o delineamento longitudinal não se aplica apenas a estudos de muito longo prazo e com muitos indivíduos. Na Psicologia do Desenvolvimento, aquele adquire importância, pois permite que se acompanhe o desenvolvimento dos indivíduos no tempo, considerando múltiplas variáveis que afetam o desenvolvimento.

Para Thoman (1979), é pelo estudo das mudanças do bebê que se tornará possível compreender processos de desenvolvimento pelos quais o bebê modifica e é modificado pelo ambiente. 
Em relação ao contexto em que as expressividades foram investigadas, predominam os estudos em ambiente naturalístico, em creche e em domicílio, exceto em três casos que envolveram ambiente hospitalar e de laboratório (Pantoja \& Nelson-Goens, 2000; Bergamasco, 1997; Chóliz, Fernández-Abascal, \& Martínez-Sánchez, 2012).

Esses contextos, no entanto, aparecem como um termo genérico (casa, creche, hospital). Porém, como discutem Moura e Ribas (2000), ainda são poucas as iniciativas de discussão conceitual sobre o contexto para conceber o desenvolvimento psicológico como ocorrendo de forma indissociada do contexto sociocultural.

Ainda vários autores vêm apontando para a necessidade de se privilegiarem estudos naturalísticos, particularmente no âmbito do desenvolvimento, considerando a complexidade das relações e os contextos experimentados pela criança (Clark, 1978; Trevarthen \& Aitken, 2001).

As pesquisas que se utilizam das videogravaçôes, em sua maioria, têm os bebês como foco; já as entrevistas e outros métodos têm como centro os adultos (familiares e educadoras) falando sobre o bebê. Como Gottlieb (2009) afirma, muitas vezes, é tentador permitir que outras pessoas falem pelos bebês, que os estudos "dos bebês" se tornem estudos da primeira infância vista "pelos outros". Para ela, é preciso incluir os próprios bebês nos estudos.

Essa tem sido a posição de vários pesquisadores, deixando de estudar o bebê de modo mais assujeitado aos adultos (Lemos, 1986), o que pode permitir apreender o modo como os papéis sociais (inscritos em cada fragmento do discurso e da relação) são gradualmente assumidos e organizados pela criança e que é desse processo que emerge a possibilidade de ela conceber a si e ao outro, como sujeitos. Nesse sentido, vários psicólogos do desenvolvimento e psicanalistas (Amorim et al., 2000; Fogel, 1993; Stern, 1992) vêm adotando modelo de análise dos bebês em suas dialógicas interações, buscando apreender o papel deles de forma mais ativa.

Tendo explorado essas questôes metodológicas, apresenta-se, na sequência, os resultados dos artigos sobre quais expressividades emocionais são investigadas nos estudos.

\subsection{As expressividades emocionais manifestas por bebês nos estudos}

As manifestações emocionais encontradas nos artigos analisados ora são mencionadas como expressividades, ora como comportamentos. Ambas as formas de referir, levam a resultados de expressividade semelhantes (sorriso, 
choro, medo, etc.).

No trabalho de Melchiori e Alves (2000), comportamentos dos bebês entre 4 e 24 meses são descritos pelas educadoras, quando estes chegam na creche e são recebidos por elas. Entre os comportamentos mencionados, encontraram-se o rir ou sorrir, abraçar e beijar, chorar, resmungar, entre outros. Outro trabalho das mesmas autoras (Melchiori \& Biasoli-Alves, 2002), realizado por meio de entrevistas com as educadoras e observações, descreve o humor dos bebês (entre 4 meses a 24 meses) na rotina diária da creche, no sentido de agrupar comportamentos: chora e resmunga antes da alimentação; fica feliz quando toma banho de sol; riem ou sorriem observando o ambiente e brincando dentro da sala; ficam calmos, irritados, entre outros.

Já as autoras Saullo et al. (2013), ao apresentarem estudo de caso sobre um bebê mordedor em interação com outras crianças de creche, analisam o bebê focal abordando os dialógicos movimentos das várias pessoas, a comunicação verbal e não verbal, além das expressões faciais, incorporando posturas e gestos.

Para além dos trabalhos citados, os resultados gerais das pesquisas mencionam inúmeras emoçôes expressas por bebês, tais como riso, choro, resmungo, felicidade, impaciência, alegria, raiva, sorriso, expressôes faciais de agrado e desagrado, expressão de dor, medo, emoções positivas e emoções negativas, ansiedade, etc. (Amorim, Costa et al., 2012; Amorim, 2012; Amorim, Anjos et al., 2012; Mendes \& Moura, 2009; Deynoot-Schaub \& Riksen-Walraven, 2006; Anjos et al. 2004; Vasconcelos et al., 2003; Zanella \& Andrada, 2002).

A princípio, pode-se pensar então que os trabalhos contêm densas discussões sobre questôes concernentes à expressividade emocional. Porém o que se verificou é que, apesar de as expressões emocionais serem citadas nos artigos e evidenciadas pela descrição de alguns episódios interativos dos bebês, de modo geral, elas não são foco de discussão, uma vez que o artigo estava centrado em outras questóes. O artigo de Zanella e Andrada (2002), por exemplo, discute o processo de significação no primeiro ano de vida (bebês de 5 a 12 meses). Em relato de episódio interativo de dois bebês e uma professora, as autoras mencionam as expressividades emocionais de sorriso e choro. Apesar disso, o foco da discussão está centrado nos significados construídos no brincar, sem destaque àquelas e sequer são expressividades emocionais.

Com objetivo semelhante, o trabalho de Amorim (2012) também discute processos de significação no primeiro ano de vida de bebês de creche (5 a 12 meses de idade). Tais processos são analisados pela observação das dialógicas ações dos adultos e dos bebês nas interações; e, no comportamento dos bebês, as peculiaridades dos gestos, emoçōes, postura corporal, expressões faciais, 
entre outros. Apesar da menção às expressividades emocionais (choro, sorriso e irritação) e da discussão sobre corporeidade, as expressividades emocionais não são o foco da pesquisa, permanecendo implícitas na discussão.

Também o trabalho de Vasconcelos et al. (2003) apresenta relatos de episódios interativos de bebês em creche ( 7 a 14 meses de idade). Os autores mencionam o sorriso e o olhar emitidos entre os pares de idade, mas o foco da discussão recai sobre a incompletude motora como elemento que pode vir a favorecer interações de pares e seu desenvolvimento.

Em contraposição, o trabalho de Amorim, Anjos et al. (2012), que se propôs a investigar a interação de bebês na creche (4 a 13 meses de idade), destaca o papel do olhar como expressão que desencadeia no coetâneo inúmeras reações e, entre elas, as expressividades emocionais (alegria, choro, susto, apreensão, entre outras). Em um dos episódios descritos no artigo, as autoras afirmam que "Os próprios bebês inicialmente sorriem ao outro; depois, emitem tom incomodado e buscam pelo adulto; ou revelam expressões faciais de seriedade e tensão" (Amorim, Anjos et al., 2012, p. 382). Na discussão do trabalho, as emoções são colocadas como forma de expressão que liga, contagia e atrai os bebês (Wallon, 1979), destacando que, pelas emoções, vocalizações e movimentos do corpo, os bebês são capazes de (co)construir, (trans)formar e (re)negociar significados entre si.

Outro artigo, de Amorim, Costa et al. (2012), avança mais na discussão das expressividades emocionais de bebês, apesar de que o foco está dado na construção de significações em relações afetivas em contextos de casa, creche e abrigo. A emoção é discutida como elemento que possibilita a sociabilidade do bebê, implicando contágio e solidariedade de comportamentos (Wallon, 1999). As autoras discutem que, no ambiente da creche, devido ao reduzido número de educadores em relação à quantidade de crianças, o parceiro mais disponível nesse ambiente são os pares de idade. Tal realidade leva o bebê a lidar com várias situações, inclusive a tentar resolvê-las sem a participação dos adultos. Assim, pela menor presença direta de adultos, os bebês negociam brinquedos e objetos, as expressões emocionais servindo como canal de comunicação, contribuindo para resolver ou amplificar os conflitos.

Em contrapartida às tímidas discussões sobre emoção entre pares de bebês de creche nos estudos nacionais, encontra-se estudo desenvolvido na Holanda, com crianças entre 15 e 23 meses. Deynoot-Schaub e Riksen-Walraven (2006), em suas discussões, enfatizam que esse trabalho é um dos primeiros a avaliar longitudinalmente as interações e o ajustamento socioemocional entre os pares de idade menores de 2 anos. $\mathrm{O}$ estudo avalia as crianças mediante categorias 
de ajustamento socioemocional, designadas como comportamentos/iniciativas positivas (sorrisos) e negativas (choro, agressividade). Os resultados apontam a que, "conforme esperado", as crianças apresentam mais interações com os adultos do que com os coetâneos tanto aos 15 quanto aos 24 meses de idade. Porém os autores afirmam que, com o aumento da idade, a interação entre os pares aumenta significativamente. Apesar disso, eles afirmam que as interações são mais negativas, em forma de agressividade e competitividade.

Do mesmo modo que o artigo fala de "iniciativas positivas e negativas" entre pares de bebês, outros trabalhos alheios aos resultados desta revisão, que tratam de relações de bebês com adultos (por exemplo, Messinger, 2002), também classificam expressões emocionais de bebês como positivas ou negativas. Essa é uma questão presente na literatura, em que Mendes e Seidl-de-Moura (2009), por exemplo, referem que o sorriso é uma forma de expressão facial amplamente associada à manifestação de afeto positivo e de emoções como prazer e alegria. Ou que, Rapoport e Piccinini (2001), ao investigarem a adaptação do bebê à creche, discutem que sinais de angústia podem incluir expressões emocionais negativas.

Questão observada no conjunto dos trabalhos é de que, geralmente, a expressividade é analisada fundamentalmente com base nas manifestaçôes faciais da criança. Tem-se a hipótese de que, além de uma questão cultural, tem peso a referência mundial que é Ekman (2011). O autor focaliza a apreensão das expressões faciais como via de acesso às emoções, tendo construído um atlas da face com descrição sistemática em palavras, fotografias e filmes de como medir o movimento facial em termos anatômicos (Ekman, 2011) e que concebeu uma ferramenta para avaliar expressões emocionais, o Sistema de Codificação da Ação Facial / Facial Action Coding System (FACS).

Contrastando com essa abordagem, outros autores discutem a necessidade de apreender as expressões da emoção para além da face, incluindo elementos vocais e corporais, alegando que não é somente a face que expressa determinada emoção, o corpo todo se manifesta (Galvão, 2003; Ferreira, 2013). De acordo com eles, por esse olhar ampliado, podem-se abrir caminhos para investigar processo de desenvolvimento das emoçóes.

Finalmente, retoma-se a questão de busca da manifestação emocional na relação entre pares de bebês, tendo-se encontrado apenas alguns trabalhos que tratam do tema de forma indireta. Essa verificação, como discutido na introdução desse artigo, era de alguma forma esperada, já que, em nossa cultura, tem-se entendido que as primeiras manifestações na criança ocorrem, em geral, no contexto familiar e na relação com adultos, mais frequentemente com a 
mãe (Mendes \& Moura, 2009). Como questiona Friedmann (2005), porém, as múltiplas infâncias não têm sido investigadas. Usualmente, não se estudam bebês provenientes de famílias desestruturadas, filhos de mães solteiras, pais separados e crianças adotadas; ou crianças em abrigo, abandonadas; bebês de periferias e zonas rurais, da rua ou de diversas origens étnicas. O que há nos estudos são crianças criadas em contextos "normais". Como Friedmann (2005) afirma, o campo sofre de uma "normose", pela qual se é guiado por um conjunto de normas, conceitos, valores, estereótipos, hábitos de pensar ou agir em uma determinada sociedade, guiando as pesquisas e a construção do conhecimento.

\section{CONSIDERAÇÕES FINAIS}

Esta revisão bibliográfica, com base em um conjunto de bases de dados e critérios de inclusão/exclusão, teve por objetivo mapear o que vem e o que não vem sendo discutido sobre a expressividade emocional de bebês, permitindo verificar diferentes aspectos que permeiam as pesquisas concernentes à temática e suas implicações na prática.

Verificou-se que, no geral, apesar de estar havendo um crescimento de interesse em pesquisas na área das emoções (Mendes \& Moura, 2009), esta é ainda restrita; é mais limitada, particularmente, quando se considera emoções de bebês com pares e em contextos não domiciliares. Verificou-se pelos próprios resultados, porém, a necessidade de fazer a busca em novas bases de dados.

Outro aspecto que chama a atenção é o fato de que, no Brasil, há um número mais elevado de pesquisas mais próximas dessa temática, em comparação a outros países. Tal resultado pode estar relacionado a políticas públicas adotadas no país, em que se tem menor tempo de licença maternidade e, simultaneamente, maior investimento na educação infantil em creches (Rutanen et al., 2014). De qualquer forma, devido às mudanças sociais (ingresso maciço da mulher no mercado de trabalho) e ao crescente compartilhamento da educação de crianças pequenas com instituições do tipo creche, faz-se urgente a condução de investigaçõos que apreendam o desenvolvimento do bebê em contextos e relações diversas. Tal necessidade se mostra clara pelo baixo número de publicações sobre emoções em bebês, particularmente nas relações com pares de idade (Lewis, 2005). Enfatizase que, nos contextos institucionais de educação, o outro bebê é o parceiro mais frequente e disponível, havendo a necessidade de pesquisas que investiguem o que acontece entre os pares, para a construção de conhecimento que leve a orientações inclusive quanto à prática pedagógica com bebês naqueles ambientes.

No que diz respeito especificamente ao tema de busca (a expressividade emocional em bebês), destaca-se o grande número de estudos que observam a 
emoção centralmente pela face do bebê. Contudo se verificou a necessidade de pensar na condução de estudos que apreendam aquela expressividade por meio de toda a corporeidade do bebê.

Em relação às metodologias adotadas, a maior parte dos estudos foi conduzida por videogravaçôes. Esse dado revela a peculiaridade do objeto em estudo (expressividade em bebês), que impõe a necessidade de recursos que permitam a verificação daquelas manifestações tão breves e sutis (Beebe, 1982).

Ainda, a maior parte dos estudos não élongitudinal (impossibilitando apreender processos de transformação ao longo do tempo) e é conduzido particularmente na análise da relação com o adulto, em que muitos falam sobre o bebê. No sentido de se pensar a compreensão de aspectos do desenvolvimento humano, porém, aponta-se à pertinência de estudos empíricos com delineamentos longitudinais e em ambiente naturalístico, com técnicas de coleta de dados que possibilitem apreender a dinâmica interacional em tempo real nas formas como ocorrem as vivências e os processos expressivos entre os bebês, considerando elementos de ordem cultural e social que permeiam tal dinâmica.

Levando em conta os elementos analisados, tem-se a hipótese de que há uma riqueza de expressividades emocionais já presentes no primeiro ano de vida dos bebês, que podem manifestar-se nas relações entre os pares; ainda, que essas formas de expressão se dão como que em um diálogo não verbal entre os bebês, podendo vir a favorecer o desenvolvimento social e emocional dos infantes. Para verificar tal hipótese, são necessárias novas pesquisas empíricas, tanto para favorecer suporte teórico quanto para resultar em subsídios de atuação a profissionais da área da educação infantil e à Psicologia do Desenvolvimento Humano. 


\section{REFERÊNCIAS}

Amorim, K. S. (2012). Processos de significação no primeiro ano de vida. Psicologia: Teoria e Pesquisa, 28, 45-53.

Amorim, K. S., Anjos, A. M., \& Rossetti-Ferreira, M. C. (2012). Processos interativos de bebês em creche. Psicologia: Reflexão e Critica, 25, 378-389.

Amorim, K. S., Costa, C. A., Rodrigues, L. A., Moura, G. G., \& Ferreira, L. D. I. P. M. (2012). O bebê e a construção de significações, em relações afetivas e contextos culturais diversos. Temas em Psicologia, 20, 309-326.

Amorim, K. S. \& Rosetti-Ferreira, M. C. (1999a). Análise crítica de investigação sobre doenças infecciosas respiratórias em crianças que frequentam creche. Jornal da Pediatria, 75(5), 313-320.

Amorim, K. S. \& Rossetti-Ferreira, M. C. (1999b). Creches com qualidade para a educação e o desenvolvimento integral da criança pequena. Psicologia: Ciência e Profissão, 19(2), 64-69.

Amorim, K. S. \& Rossetti-Ferreira, M. C. (2008). Corporeidade, significação e o primeiro ano de vida. Arquivos Brasileiros de Psicologia, 60, 67-81.

Amorim, K. S., Vitória, T. \& Rossetti-Ferreira, M. C. (2000). A rede de significações como perspectiva para a análise do processo de inserção de bebês na creche. Cadernos de Pesquisa, 109, 115-144.

Anjos, A. M., Amorim, K. S., Vasconcelos, C. R. F., \& Rossetti-Ferreira, M. C. (2004). Interações de bebês em creche. Estudos de Psicologia, 9, 513-522.

Balda, R. C., Almeida, M. F. B., Peres, C. A., \& Guinsburg, R. (2009). Fatores que interferem no reconhecimento por adultos da expressão facial de dor no recém-nascido. Revista Paulista de Pediatria, 27(2), 160-167.

Beebe, B. (1982). Micro-timing in mother-infant communication. In M. R. Key (Ed), Nonverbal communication today. (pp. 169-195). New York: Mounton.

Belsky, J. (2009). Early day care and infant-mother attachment security. Encyclopedia on Early Childhood Development, 1-6.

Bergamasco, N. H. P. (1997). Expressão facial como acesso à consciência do recém-nascido. Psicologia USP, 8, 275-286.

Bowlby, J. (1969). Apego e perda (2a ed.). A. Cabral (Trad.). (Vol 1.) São Paulo: 
Martins Fontes, 1990. (Publicado originalmente publicado em 1969).

Bowlby, J. (1989). Uma base segura: aplicaçôes clínicas da teoria do apego. Porto Alegre: Artes Médicas.

Branningan, C. R. \& Humphries, D. A. (1981). Comportamento não verbal humano, um meio de comunicação. In N. Blurton-Jones (Org.), Estudos Etológicos do Comportamento da criança. (pp. 37-66). São Paulo: Biblioteca Pioneira de Ciências Sociais.

Brownell, C. A., Ramani, G. B. \& Zerwas, S. (2006). Becoming a social partner with peers: cooperation and social understanding in one-and-two-year-olds. Child Development, 77, 803-821.

Carvalho, A. M. A. (2005). Em busca da natureza do vínculo: uma reflexão psicoetológica sobre grupos familiares e redes sociais. In J. C. Petrini \& V. R. Cavalcanti (Orgs.), Família, sociedade e subjetividades: uma perspectiva multidisciplinar. (pp. 183-194). Rio de Janeiro: Vozes.

Carvalho, A. M. A., Bergamasco, N. H. P., Lyra, M. C. D. P., Pedrosa, M. I. P. C., Rubiano, M. R. B., Rossetti-Ferreira, M. C., . . . , Vasconcellos, V. M. R. (1996). Registro em vídeo na pesquisa em psicologia: reflexões a partir de relatos de experiência. Psicologia: Teoria e Pesquisa, 12(3), 261-267.

Chóliz, M., Fernández-Abascal, E. G., \& Martínez-Sánchez, F. (2012). Infant crying: pattern of weeping, recognition of emotion and affective reactions in observers. The Spanish Journal of Psychology, 15, 978-988.

Clark, R. A. (1978). The transition from action to gesture. In A. Lock (Ed.), Action, gesture and symbol: the emergence of language. (pp. 231-257). London: Academic Press.

Costa, C. A. \& Amorim, K. S. (2015). Abreviação em relações de bebês com seus pares de idade. Psicologia: Teoria e Pesquisa, 31(1), 15-23.

Darwin, C. (2000). A expressão das emoções no homem e nos animais. São Paulo: Companhia das Letras.

Lemos, C. T. G. (1986). Interacionismo e aquisição de linguagem. Delta, 2(2), 231-248.

Deynoot-Schaub, M. G. \& Riksen-Walraven, J. M. (2006). Peer interaction in child care centers at 15 and 23 months: stability and links with children's 
socio-emotional adjustment. Infant Behavior \& Development, 29, 276-288.

Early Child Care Research Network. (2007). Age of entry to kindergarten and children's academic and socioemotional development. Early Education \& Development, 18(2), 337-368.

Ekman, P. (2011). A linguagem das emoções. São Paulo: Lua de Papel.

Esperidião-Antonio, V., Majeski-Colombo, M., Toledo-Monteverde D., MoraesMartins, G., Fernandes, J. J., Assis, M. B., \& Siqueira-Batista, R. (2008). Neurobiologia das emoções, Revista de Psiquiatria Clínica, 35(2), 55-65.

Ferreira, L. D. I. P. M. (2013). Expressões emocionais de desprazer no primeiro ano de vida: manifestações e processos de transformação. (Dissertação de Mestrado). Universidade de São Paulo, Ribeirão Preto.

Finkelstein, N. W., Dent, C., Gallacher, K., \& Ramey, C. T. (1978). Social behavior of infants and toddlers in a day-care environment. Developmental Psychology, 14, 257-262.

Fogel, A. (1993). Developing through relationships: origins of communication, self and culture. Hertfordshire: Harvester Wheatsheaf.

Freud, S. (1969). Obras psicológicas completas de Sigmund Freud. Rio de Janeiro: Imago.

Friedmann, A. (2005). O universo simbólico da criança. Petrópolis: Vozes.

Galvão, I. (2003). Expressividade e emoção segundo a perspectiva de Wallon. In I. Arantes, Afetividade na escola: alternativas teóricas e práticas. (pp. 71-88). São Paulo: Summus.

Garvey, A. \& Silva, M. (2010). Desenvolvimento da comunicação, identidade e emoções na infância: contribuições das perspectivas relacional e dialógica. Educar, 36, 55-64.

Gottlieb, A. (2009). Para onde foram os bebês? Em busca de uma antropologia de bebês (e de seus cuidadores). Psicologia USP, 20(3), 313-336.

Lewis, M. (2005), The children and its family: the social network model. Human Development, 48, 8-27.

Lima, A. P. R. (2012). Os bebês entre eles: afinal, há interação? Pró-Posições, 23, 235-238. 
Melchiori, L. E. \& Alves, Z. M. M. B. (2000). Comportamento de bebês em situações de separação e reencontro com os pais, na rotina diária da creche. Paidéia (Ribeirão Preto), 10(18), 51-59.

Melchiori, L. E. \& Alves, Z. M. M. B. (2004). Estratégias que educadoras de creche afirmam utilizar para lidar com o choro dos bebês. Interação em Psicologia, 8, 35-43.

Melchiori, L. E. \& Biasoli-Alves, Z. M. M. (2002). Comportamento de bebês na rotina diária da creche. Revista Brasileira de Crescimento e Desenvolvimento Humano, 12(2), 39-51.

Mendes, D. M. L. F. \& Moura, M. L. S. D. (2009). Expressões faciais de emoção em bebês: importância e evidências. Estudos e Pesquisas em Psicologia, 9(2), 307-327.

Mendes, D. M. L. F. \& Seidl-de-Moura, M. L. (2009). O sorriso humano: aspectos universais, inatos e os determinantes culturais. Arquivos Brasileiros de Psicologia, 61(1), 109-120.

Messinger, D. S. (2002). Positive and negative: infant facial expressions and emotions. Current Directions in Psychological Science, 11, 1-6.

Mota, M. M. P. E. (2010). Metodologia de pesquisa em desenvolvimento humano: velhas questôes revisitadas. Psicologia em Pesquisa, 4, 144-149.

Moura, M. L. S. \& Ribas, A. F. P. (2000). Desenvolvimento e contexto sociocultural: a gênese da atividade mediada nas interações iniciais mãe-bebê. Psicologia Reflexão e Crítica, 13(2), 245-256.

Nyland, B. (1999). Listening to infants: emotional literacy and the childcare setting. International Journal of Early Childhood, 31, 99-104.

Pantoja, A. P. F. \& Nelson-Goens, G. C. (2000). Desenvolvimento da vida emocional durante o segundo ano de vida: Narrativas e sistemas dinâmicos. Psicologia: Reflexão e Crítica, 13, 269-280.

Rapoport, A. \& Piccinini, C. A. (2001). O ingresso e adaptação de bebês e crianças pequenas à creche: Alguns aspectos críticos. Psicologia: Reflexão e Critica, 14, 81-95.

Reis, A. O. A. (1991). A criança integral e as teorias do desenvolvimento. Revista Brasileira de Crescimento e Desenvolvimento Humano, 1(1), 71-82. 
Ribeiro, F. J. L., Bussab, V. R. \& Otta, E. (2004). De colo em colo, de berço em berço. In M. L. S. de Moura (Org.), O bebê do século XXI e a psicologia em desenvolvimento. (pp. 229-284). São Paulo: Casa do Psicólogo.

Rossetti-Ferreira, M. C., Amorim, K. S. \& Vitória, T. (1994). A creche enquanto contexto possível de desenvolvimento da criança pequena. Revista Brasileira de Crescimento e Desenvolvimento Humano, 4(2), 35-40.

Rossetti-Ferreira, M. C., Oliveira, Z. M. R., Carvalho, M. I. C. \& Amorim, K. S. (2010). Peer relations in Brazilian daycare centres: a new focus for early childhood education. In M. Kernan \& E. Singer (Org.), Peer relationships in early childhood education and care. (pp. 74-87). Londres: Routledge Taylor \& Francis Group.

Rouchouse, J. C. (1978). Human ethology and nonverbal communication among infants. Enfance, 1, 13-30.

Rutanen, N., Amorim, K. S., Colus, K. M. \& Piattoeva, N. (2014). What is best for the child? Early childhood education and care for children under 3 years of age in Brazil and in Finland. International Journal of Early Childhood, 46, 123-141.

Saullo, R. F. M., Rossetti-Ferreira, M. C., \& Amorim, K. S. (2013). Cuidando ou tomando cuidado? Agressividade, mediação e constituição do sujeito: um estudo de caso sobre um bebê mordedor em creche. Pró-Posiçôes, 24, 81-98.

Stern, D. (1992). O mundo interpessoal do bebê: uma visão a partir da psicanálise e da psicologia do desenvolvimento. Porto Alegre: Artes Médicas.

Thoman, E. B. (1979). Changing views on the being and becoming of infants. In E. B. Thoman (Ed.), Origins of the infant's social responsiveness. (pp. 445459). New York: John Wiley Sons.

Trevarthen, C. \& Aitken, K. J. (2001). Infant intersubjectivity: research, theory and clinical applications. Journal of Child Psychology and Psychiatry, 42(1), $3-48$.

Vasconcelos, C. R. F., Amorim, K. S., Anjos, A. M. \& Ferreira, M. C. R. (2003). A incompletude como virtude: interação de bebês na creche. Psicologia: Reflexão e Critica, 16, 293-301.

Wallon, H. (1999). A atividade proprioplástica. In M. J. G. Werebe, \& J. NadelBrulfert (Orgs.), Henri Wallon. (2a ed.). (pp. 141-148). São Paulo: Ática, 1999. 
Wallon, H. (1979). Do ato ao pensamento. Lisboa: Moraes.

Weltzer, H. (1985). Teaching infants infant-infant social interaction. Early Child Development and Care, 20, 145-155.

Winnicott, D. W. (1987). Privação e delinquência. São Paulo: Martins Fontes.

Zanella, A. V. \& Andrada, E. G. C. (2002). Processos de significação no brincar: problematizando a constituição do sujeito. Psicologia em Estudo, 7, 127-133. 